Published in final edited form as:

Curr Opin Organ Transplant. 2015 August ; 20(4): 369-375. doi:10.1097/MOT.0000000000000204.

\title{
Role of B cells in Tolerance Induction
}

\author{
James I. Kim ${ }^{1}$, David M. Rothstein ${ }^{2}$, and James F. Markmann ${ }^{1}$ \\ ${ }^{1}$ Center for Transplantation Sciences, Massachusetts General Hospital, Harvard Medical School, \\ 55 Fruit Street, Thier 8, Boston, MA 02114
}

${ }^{2}$ Thomas E. Starzl Transplantation Institute, University of Pittsburgh Medical School, 200 Lothrop Street, E1555 Biomedical Science Tower, Pittsburgh, PA 15261

\begin{abstract}
Purpose-B cells are known to play a central role in humoral immunity and to boost cellular immunity, however, in a variety of experimental models, B cell subsets ameliorate inflammation and autoimmune disease, indicating that they can also play a regulatory role. Here we highlight the advances in regulatory B cell (Breg) biology of the past year with an emphasis on findings pertinent to transplantation. Several recent observations highlight the relevance to clinical transplantation. Data from at least three independent groups demonstrated that spontaneously tolerant renal transplant recipients exhibit a peripheral blood B cell signature although the significance of these data remains unclear. Moreover, new data suggest that regulatory B cells may serve as a biomarker for long-term allograft outcomes. Finally, recent evidence suggesting that plasma cells may be an essential component of Bregs raises new concerns about targeting antibody producing cells.
\end{abstract}

Recent findings-We describe new information on Breg mechanisms of action to suppress the alloresponse, signals to expand Bregs in vitro, and more functional evidence of Breg involvement in operationally tolerant kidney patients and in maintaining stable allograft function.

Summary-While lymphocyte depletion remains central to tolerance induction therapy, the sparing or expansion of regulatory B cells may be an additional strategy to preempt graft rejection.

\section{Keywords}

regulatory B cells; IL-10; ritixumab; transplant tolerance

\section{Introduction}

B cells are central to antibody-mediated rejection and enhance the cellular immune response. However, there is accumulating evidence for regulatory B cell subpopulations capable of ameliorating inflammation and maintaining tolerance. Breg function is now implicated in autoimmunity, tumor immunity, infectious disease, and the response to transplants (1). Understanding the B cell influence on transplant outcome is complicated by the varying roles of numerous B cell subpopulations.

Corresponding Author: James I. Kim, phone: 617643 0373, jkim35@mgh.harvard.edu.

Conflicts of interest: none. 


\section{Phenotypic identification of Bregs}

The inability to definitively identify Bregs remains a major challenge to fully understanding their immunobiology. In most studies, IL-10 is essential for Breg activity, and B cell IL-10 expression remains the most unified approach towards defining Bregs (2, 3). However, the IL-10 protein is essentially undetectable in freshly isolated B cells, and therefore IL-10 expression has not been a useful means to isolate Bregs for direct study. Rather, IL-10 is usually detected only after in vitro stimulation with mitogens, TLR ligands, and/or CD40 ligation. For example, after stimulation with LPS, ionomycin, and PMA, for 5 hours, $1 \%$ of total B cells express IL-10 (4). Unfortunately, there is no specific cell surface marker for such IL-10+ B cells.

While there is no specific marker, the frequency of IL-10+ B cells after in vitro stimulation is clearly enriched in certain B cell subsets, and these generally exhibit Breg activity upon adoptive transfer. For example, splenic marginal zone (MZ) (5-7), MZ-precursor (MZ-P) or Transitional 2 (T2) (8-11), follicular (FO) (7, 9, 12), CD1dhi CD5+ B cells (13), pro-B cells (14), and even plasma cells $(15,16)$ have been shown to exert regulatory activity. Nevertheless, IL-10+ cells still remain a minority of the B cells even within these enriched subsets (e.g. 10-25\%). In adoptive transfer, those subsets that have the most IL-10+ regulatory B cells, and presumably the fewest pro-inflammatory B cells, will appear to be regulatory in any given model. Thus, regulatory activity upon adoptive transfer is primarily a measure of frequency of IL-10+ B cells in that select population. Moreover, most such regulatory subsets only account for a fraction of all IL-10+ B cells which are generally dispersed in multiple B cell fractions at lower frequency (17). However, it is not currently known whether all B cell subsets expressing IL-10 function as Bregs, nor is it known whether IL-10-B cells within functional Breg subsets can also contribute to the observed Breg activity. In this regard, IL-35 is expressed by a distinct subset of B cells (especially plasma cells), and these cells may play a co-dominant role along with IL-10+ B cells in regulating experimental autoimmune encephalomyelitis (EAE) $(15,16)$.

The frequency of IL-10 expression by B cells can be increased 4-5 fold by more prolonged in vitro stimulation (e.g. CD40 ligation for 2-3 days prior to mitogenic stimulation) (2). Whether the increase in IL-10+ B cells represents stochastic expression of IL-10 by activated B cells, or is due to in vitro maturation of Breg progenitors as has been suggested (2), remains unclear since there are no transcription factors or other markers that identify Bregs as a lineage. On the other hand, stimulation of bone marrow cells with TLR ligands in vitro can give rise to pro-B cells that can prevent onset of diabetes upon transfer into prediabetic NOD mice (14). These cells clearly develop into mature B cells after transfer, although it is unclear which subset/maturation state is responsible for the suppressive effect observed.

\section{Mechanism of action}

In the mouse, Bregs alter $\mathrm{T}$ cell effector function by decreasing Th1 and Th17 differentiation while increasing the presence of Tregs $(7,9,10,13,15,18-25)$. Graft survival prolongation by Breg adoptive transfer is Treg-dependent, and transfer increases the number and 
frequency of Tregs, which is likely dependent on B cell expression of TGF- $\beta(25,26)$. In the presence of Bregs, DCs decrease their antigen presenting capacity and increase their production of IL-4 while decreasing their production of IL-12 (24). Finally, induction of Bregs by LPS stimulation results in FasL upregulation which may kill target cells and TGF$\beta$ upregulation which decreases antigen presentation by APCs and promotes Tregs (14, 27, 28).

While most studies show a critical role for IL-10, others show IL-10-independent mechanisms of Breg action. For example, B cells reduce severity of EAE, and IL-10 production by B cells was necessary for this B cell suppressor activity $(15,16,18,29)$. On the other hand, it has also been reported that B cell GITRL expression and not IL-10 expression played an essential role in maintaining Treg numbers and reducing EAE severity (30). In an MHC class I-disparate skin graft model, adoptive transfer of B cells from tolerant mice was able to prolong graft survival in a dose-dependent and antigen-specific manner (31). Only transitional-2 B cells from tolerized mice, not marginal zone or follicular or transitional-1 B cells, could prolong skin graft survival upon adoptive transfer. Interestingly, while T2 cells expressed elevated levels of the TIM-1 marker (considered below), in vivo T2 suppressor function was not IL-10-dependent as demonstrated by adoptive transfer of IL-10-/- B cells. Of note, earlier studies from Mauri's group (9) showed that T2 B cells prevented collagen-induced arthritis in an IL-10-dependent manner and that naive T2 cells could also inhibit disease, although they were less potent. This raises the question as to whether the potency of the alloresponse requires different mechanisms to effect suppression in the skin graft model.

Two papers implicate IL-35 as a cytokine necessary for Breg function in the recovery from autoimmune disease $(32,33)$. IL-35 is a potent immunosuppressive cytokine produced by natural Foxp3+ Tregs and induces suppressor T cells that suppress via IL-35 and independent of IL-10 or TGF- $\beta(34,35)$. The majority of IL-10 expressing B cells express IL-35 (34). In vitro culture experiments demonstrate that IL-35 may act in a positive feedback loop to generate more IL-35 production as well as IL-10 production (33). Mice with a B cell-specific deletion of IL-35, like B cell-specific IL-10-deficient knockouts, lack the spontaneous remission in EAE observed in WT animals. Both IL-10 and IL-35 knockouts demonstrate elevated CD4+ T cell infiltration in the central nervous system and a higher activation of inflammatory $\mathrm{T}$ cells (36). Of note, the highest producers of both cytokines were plasmablasts, raising the important notion that plasma cells may be important contributors to what has been viewed as Breg activity. This has been confirmed in the EAE models, showing that B cells that could not differentiate into plasma cells were not protective in EAE (16). If this finding extends to the allograft setting, it suggests that antiplasma cell therapy like B cell depletion, may not only inhibit alloantibody production but may deplete regulatory cells that promote stable engraftment (37).

Deletion of the IL-35 receptor has a significant impact on the frequency of IL-10+ Bregs while the absence of B cell IL-35 has only a modest impact (32, 33). Likewise, IL-35 receptor deficiency (IL-12R $\beta 2-/-$ ) resulted in more severe autoimmune uveitis while IL-35deficient mice demonstrated comparable disease severity to WT animals suggesting there are alternative pathways to Breg expansion $(33,36)$. Co-culture of human B cells with 
phorbol ester and IL-35 also induced IL-10 expression suggesting a potentially important means to induce IL-10+ Bregs in vitro (discussed further below).

\section{TIM-1 an inclusive marker for Bregs involved in induction and maintenance of Bregs}

TIM-1, a member of the T immunoglobulin and mucin domain family of costimulatory molecules, was originally described as a $\mathrm{T}$ cell costimulatory marker but was demonstrated to be constitutively expressed on a subset (6-8\%) of B cells (17). Depending on the B cells subset, $6-40 \%$ of TIM-1+ B cells express IL-10. Nonetheless, in every subset, TIM-1+ B cells are 10-30-fold enriched for IL-10 compared to their TIM-1-counterparts. Thus, while not specific, TIM-1 identifies over $70 \%$ of all IL-10+ B cells, making this the most inclusive marker of IL-10+ B cells identified thus far (17). Since TIM-1+ B cells belong to multiple subsets, these data suggest that IL-10+ B cells from different B cell subpopulations may contribute to Breg activity. In this regard, TIM-1+ but not TIM-1-B cells from alloimmunized mice transfer long-term islet allograft survival into otherwise untreated Bdeficient recipients, and IL-10 expression in transferred B cells was essential for prolonged graft survival (17). Adoptive transfer of TIM-1+ Bregs polarizes Th cells towards a less inflammatory cytokine profile with increased IL-10 and IL-4 and reduced IFN- $\gamma(17,25)$.

Several lines of evidence indicate that TIM-1 may be more than just a marker for IL-10+ Bregs. First, TIM-1 ligation alone, or in combination with anti-CD45RB, increases both the frequency and number of TIM-1+ and IL-10+ B cells and prolongs allograft survival (17, 38). While tolerance induced by anti-TIM-1 is Treg-dependent $(38,39)$, the expression of TIM-1 on Tregs is minimal (17). In contrast, the induction of tolerance, Tregs, and antiinflammatory Th skewing by anti-TIM-1 are all dependent on B cells $(17,38)$. Therefore, anti-TIM-1 induces IL-10+ Bregs.

Second, mice expressing a TIM-1 mutant lacking the mucin domain (TIM-1 ${ }^{\Delta \mathrm{muc}}$ ) exhibit a baseline defect in number and frequency of IL-10+ B cells that progresses with age $(40,41)$. In non-autoimmune strains, these mice develop spontaneous age-related $\mathrm{T}$ cell hyperresponsiveness, splenomegaly, autoantibodies, and multi-organ inflammation $(40,42)$. Moreover, even young TIM- $1^{\Delta \mathrm{muc}}$ mice exhibit accelerated rejection of single class II MHC mismatched (bm12) heart allografts, and simple transfer of naive WT TIM-1+ B cells into these mice at the time of transplant markedly prolongs allograft survival, with $50 \%$ of mice exhibiting long-term engraftment (41). Moreover, after transfer of WT but not TIM- $1^{\Delta \mathrm{muc}} \mathrm{B}$ cells into B-deficient hosts, anti-TIM-1 antibody augments IL-10 expression and prolongs islet allograft survival (41). Similarly, both TIM-1 ${ }^{\Delta \text { muc }}$ and TIM-1-/- B cells are defective in IL-10 expression after in vitro stimulation and exhibit augmented Th17 and reduced Foxp3 and IL-10 polarization of T cells compared to WT B cells (40). Finally, unlike WT B cells, TIM-1 ${ }^{\Delta \text { muc }}$ and TIM-1-/- B cells cannot reduce EAE severity when transferred into B deficient hosts.

Third, rapid clearance of apoptotic cells is critical for disposal of dying cells in a noninflammatory manner (43). Splenic MZ and B1B cells, in particular, participate in the uptake of apoptotic cells through their expression of natural IgM which may bind apoptotic 
cells through recognition of phosphatidylserine and self-antigens as well as their location in the marginal zone (which directly receives blood flowing from the central arterioles) (44). Apoptotic cells have been shown to augment IL-10 expression by B cells that can inhibit EAE and collagen-induced arthritis $(7,45)$. This raised the possibility that TIM-1, a known phosphatidylserine receptor, links apoptotic cells and Breg induction. Indeed, we found that TIM-1 is responsible for a large majority of apoptotic cell binding to B cells (41). Neither TIM-1 ${ }^{\Delta \mathrm{muc}}$ nor TIM-1-/- B cells respond to apoptotic cells in vitro or in vivo in terms of IL-10 expression or protection from EAE $(40,41)$. These studies suggest that: TIM-1 is the main apoptotic cell receptor on B cells; TIM-1 ligation by antibodies or apoptotic cells induces B cell IL-10; loss of TIM-1 signaling inhibits Breg induction; and finally that apoptotic cell binding may help establish basal Breg levels. Finally, defects in TIM-1 or polymorphisms in the mucin domain that affect apoptotic cell binding or TIM-1 signaling results in a deficiency on Bregs that predisposes to autoimmunity and accelerated allograft rejection.

\section{Regulatory B cell expansion}

In vivo treatment of mice with anti-TIM-1 antibody (clone RMT1-10) results in an expansion of TIM-1+ regulatory B cells $(17,38)$. Antibody treatment was not necessary for Breg function but increased the frequency of TIM-1+ Bregs and that of IL-10+ B cells 4-5fold. Moreover, as noted above, anti-TIM-1-mediated allograft survival was dependent on both B cells and B cell IL-10 expression and was ineffective in the absence of B cells (17). More recently a separate anti-TIM-1 antibody (clone 5F12) was described to boost $\mathrm{B}$ cell IL-10 production but did not expand the number of Bregs in vitro. TIM-1 expression on B cells was necessary for this antibody effect as there was no effect on TIM-1-/- or on TIM-1 ${ }^{\Delta \text { muc }}$ B cells $(40,42)$. Culturing Bregs with IL-21 has previously demonstrated the most dramatic impact on B cell IL-10 production (46), and co-treatment of B cells with IL-21 and 5F12 provided a synergistic boost of IL-10 production.

\section{Human regulatory $B$ cells}

Several lines of recent evidence suggest that Bregs may have clinical relevance in transplantation. Operationally tolerant (OT) kidney transplant patients are rare recipients who have stopped taking immunosuppression by non-compliance or medical necessity (e.g. PTLD) but maintain normal graft function for more than a year (47). In 2010, the Immune Tolerance Network and the EU Tolerance Consortium independently provided evidence that OT patients exhibited a "tolerance signature" related to B cells. Analysis of microarray screens of PBMCs from OT patients demonstrated that B cell-related genes were differentially expressed compared with immunosuppressed controls $(48,49)$. In fact, a set of three of these genes distinguished tolerant from non-tolerant patients with both impressive positive and negative predictive values, but the genes did not suggest any biologic function. Importantly, comparison of the profile of tolerant kidney transplant patients with recipients of other organs suggested that the B cell signature may be unique to kidney allografts (50).

While three studies did not see an increase in overall B cell IL-10 expression in OT patients compared to stable immunosuppressed patients, Newell et al. found both an increase in 
transitional B cells and IL-10 expression by this B cell subset in tolerant patients versus stable immunosuppressed controls $(48,49,51,52)$. Importantly, none of the three manuscripts found differences between tolerant patients and healthy controls. B cell expression of IL-10 from tolerant patients was low but elevated only relative to immunosuppressed patients.

Both transitional B $\left(\mathrm{CD} 24^{\mathrm{hi}} \mathrm{CD} 38^{\mathrm{hi}}\right)$ cells and $\mathrm{CD} 27^{+}$memory B cells, especially those expressing IgM (unswitched), have been shown to be enriched for IL-10 expression, and defects in IL-10 expression may or may not be associated with autoimmune disease like SLE $(23,53,54)$. As in mice, IL-10 is expressed by a minority of human B cells in any given subset. Cells within B cell subpopulations are not uniform, and indeed, cells within these same subsets concomitantly express $\mathrm{TNFa}$, an inflammatory cytokine associated with antibody-mediated responses in mice and augmented $\mathrm{T}$ cell responsiveness in multiple sclerosis (55-57). While IL-10 expression was similarly enriched in CD27+ memory B and transitional B cells, memory B cells express much higher levels of TNFa and thus have a lower IL-10:TNFa ratio ( 1.5 vs. 0.6) (55). The IL-10:TNFa ratio correlated with potent suppression of Th1 cytokines in vitro by transitional B, but not memory B subsets. Neutralization of IL-10 blocked transitional B regulatory function while neutralization of $\mathrm{TNFa}$ uncovered regulatory function of memory $\mathrm{B}$, showing that these cytokines are involved in vitro suppressive activity.

In a study of 88 renal transplant recipients $2-15$ years after transplantation, patients with stable allograft function or with graft dysfunction but no rejection on biopsy had transitional B IL-10:TNFa ratios comparable to healthy controls (55). In contrast, patients with graft dysfunction and allograft rejection, had a decrease in transitional B number. Importantly, remaining transitional B cells exhibited a significant fall in IL-10:TNFa ratio, and lost their in vitro regulatory activity. Neither transitional B IL-10 alone, nor IL-10:TNFa ratio of total B cells correlated with rejection. Thus, the transitional B subset in humans contains both regulatory and inflammatory $\mathrm{B}$ cells, whose relative balance can change depending on the immunological status.

Importantly, the transitional B IL-10:TNFa ratio could distinguish stable grafts from those with rejection with a receiver operator curve AUC of 0.823 . Moreover, the cytokine ratio was a predictor of graft outcomes over a 3-year follow-up (55). While those with a high ratio (above the overall group mean) had stable graft function, $40 \%$ of those with low ratios had a greater than two-fold decrease in GFR. Even amongst the 22 patients with rejection at time of biopsy, a low cytokine ratio showed a strong trend towards poor outcome.

The role of transitional B cells as a biomarker is further supported in a recent prospective study of 73 renal allograft patients, where a higher frequency of transitional B cells within the total B cell pool, measured at various time-points in the first year, was associated with a reduced frequency of allograft rejection (hazard ratio 0.6)(58). Interestingly, although the groups exhibit significant overlap, patients without rejection exhibited a higher percentage of transitional B cells pre-transplantation an on day 14 post-transplant, compared to those with rejection. Taken together, these findings suggest that transitional B cell number and 
perhaps more specifically, cytokine ratio varies with immunological reactivity and may serve as a biomarker for outcome.

Several other groups have also examined B cell profiles in kidney transplant patients. A comparison of those stable off drug versus immunosuppressed patients demonstrated higher levels of peripheral B cells compared to patients who experienced an acute rejection episode (59). In a comparison with calcineurin inhibitor-treated patients, belatacept-treated patients were found to have significantly higher transitional and naive $\mathrm{B}$ cell frequencies and consequently a lower percentage of memory B cells (60).

A study to examine the benefit of B cell depletion by Rituximab as the sole induction therapy suggested that depletion promoted acute graft rejection, and further recruitment was halted after six patients (61). It was hypothesized that depletion resulted in a loss of regulatory B cell activity and an inflammatory cytokine storm which potentially activated $\mathrm{T}$ cells. While in mice, B cell depletion does not accelerate acute rejection, it does augment Th1 cytokine responses and prevents tolerance induction by various agents $(11,17,38,62-$ 67). A separate larger study of Rituximab treatment as induction therapy for kidney transplant patients demonstrated that at two years post-transplant, a single dose of Rituximab did not improve the overall incidence of acute allograft rejection except potentially in immunologically high risk patients (68).

On the other hand data suggests that B cell depletion could also be used to augment relative numbers of Bregs in vivo. For example, the treatment of patients with SLE or renal allograft recipients with anti-CD20 (Rituximab), results in expansion of immature transitional B cells during the reconstitution phase $(69,70)$. To the degree that emerging cells are enriched in Bregs as opposed to proinflammatory cells, such strategies may be useful in promoting tolerance. In this regard, Liu et al. showed B cell depletion with Rituximab was synergistic with thymoglobulin and rapamycin monotherapy (200 days), resulted in marked prolongation of islet allografts in non-human primates (in some cases to $>4$ years). Interestingly, long-term survival was associated with relative expansion of transitional B cells, whereas rejection was associated with re-emergence of memory B cells (71). These findings prompted an ongoing trial sponsored by the Immune Tolerance Network (NCT01318915) in which well-matched live donor renal transplant patients receive B cell depletion in addition to Thymoglobulin induction followed by maintenance immunosuppression with Tacrolimus and Rapamycin.

\section{Conclusions}

The Tedder group has demonstrated impressive improvement of clinical outcomes in the EAE model upon adoptive transfer of ex vivo expanded Bregs. In parallel to ex vivo expanded Tregs, in the coming years we hope to see prolongation of allograft survival with adoptively transferred ex vivo expanded Bregs. Evidence is mounting that it may also be possible to capitalize on in vivo induced Bregs to promote allograft survival. Strategies to actually expand Bregs in vivo have not yet been extended to preclinical models. However, the relative increase in Bregs after B cell depletion may explain synergy of Rituximab with thymoglobulin in non-human primates and this is now being examined in humans. We 
anticipate that better identification of Breg phenotype and the role of plasma cells will help in both diagnostic and prognostic studies and will also improve therapeutic targeting to avoid Breg depletion.

Bregs have been identified in the inflammatory settings, yet their presence is not sufficient to mitigate disease. It is possible that Bregs, like Tregs, are less potent in the face of inflammatory signals such as TLR-ligands. However, this contradicts findings that TLRligands are potent induces of IL-10 expression and Bregs in vivo and in vitro. Thus, the effect inflammatory signals on Breg effectiveness and stability, as well as their site of action in vivo, remains to be determined. It remains likely that the endogenous Breg response is normally insufficient to prevent allograft rejection in the face of an overwhelming inflammatory response. Identifying how to best to augment the Breg response relative to the effector response, and avoid Breg depletion, remain important goals that are critical to optimal therapeutic application of Bregs.

\section{Acknowledgments}

We thank members of our respective labs for conversations, which led to the writing of this review.

Financial support and sponsorship: This work is supported by NIH grants AI097361 to DMR and AI057851 to JFM.

\section{References}

1. Tedder TF. B10 cells: a functionally defined regulatory B cell subset. J Immunol. 2015 Feb 15; 194(4):1395-401. [PubMed: 25663677]

2. Dilillo DJ, Matsushita T, Tedder TF. B10 cells and regulatory B cells balance immune responses during inflammation, autoimmunity, and cancer. Ann N Y Acad Sci. 2010 Jan.1183:38-57. [PubMed: 20146707]

3. Mauri C, Blair PA. Regulatory B cells in autoimmunity: developments and controversies. Nat Rev Rheumatol. 2010 Nov; 6(11):636-43. [PubMed: 20856268]

4. Yanaba K, Bouaziz JD, Matsushita T, Magro CM, St Clair EW, Tedder TF. B-lymphocyte contributions to human autoimmune disease. Immunol Rev. 2008 Jun.223:284-99. [PubMed: 18613843]

5. Brummel R, Lenert P. Activation of marginal zone B cells from lupus mice with type A(D) CpGoligodeoxynucleotides. J Immunol. 2005 Feb 15; 174(4):2429-34. [Comparative Study Research Support, U.S. Gov't, P.H.S.]. [PubMed: 15699180]

6. Lenert P, Brummel R, Field EH, Ashman RF. TLR-9 activation of marginal zone B cells in lupus mice regulates immunity through increased IL-10 production. J Clin Immunol. 2005 Jan; 25(1):2940. [PubMed: 15742155]

7. Gray M, Miles K, Salter D, Gray D, Savill J. Apoptotic cells protect mice from autoimmune inflammation by the induction of regulatory B cells. Proc Natl Acad Sci U S A. 2007 Aug 28; 104(35):14080-5. [PubMed: 17715067]

8. Mizoguchi A, Mizoguchi E, Takedatsu H, Blumberg RS, Bhan AK. Chronic intestinal inflammatory condition generates IL-10-producing regulatory B cell subset characterized by CD1d upregulation. Immunity. 2002 Feb; 16(2):219-30. [PubMed: 11869683]

9. Evans JG, Chavez-Rueda KA, Eddaoudi A, Meyer-Bahlburg A, Rawlings DJ, Ehrenstein MR, et al. Novel suppressive function of transitional 2 B cells in experimental arthritis. J Immunol. 2007 Jun 15; 178(12):7868-78. [PubMed: 17548625]

10. Blair PA, Chavez-Rueda KA, Evans JG, Shlomchik MJ, Eddaoudi A, Isenberg DA, et al. Selective targeting of B cells with agonistic anti-CD40 is an efficacious strategy for the generation of 
induced regulatory T2-like B cells and for the suppression of lupus in MRL/lpr mice. J Immunol. 2009 Mar 15; 182(6):3492-502. [PubMed: 19265127]

11. Lal G, Nakayama Y, Sethi A, Singh AK, Burrell BE, Kulkarni N, et al. Interleukin-10 From Marginal Zone Precursor B-Cell Subset Is Required for Costimulatory Blockade-Induced Transplantation Tolerance. Transplantation. 2015 Apr 3.

12. Miyazaki D, Kuo CH, Tominaga T, Inoue Y, Ono SJ. Regulatory function of CpG-activated B cells in late-phase experimental allergic conjunctivitis. Invest Ophthalmol Vis Sci. 2009 Apr; 50(4):1626-35. [PubMed: 19060266]

13. Yanaba K, Bouaziz JD, Haas KM, Poe JC, Fujimoto M, Tedder TF. A regulatory B cell subset with a unique CD1dhiCD5+ phenotype controls T cell-dependent inflammatory responses. Immunity. 2008 May; 28(5):639-50. [PubMed: 18482568]

14. Montandon R, Korniotis S, Layseca-Espinosa E, Gras C, Megret J, Ezine S, et al. Innate pro-B-cell progenitors protect against type 1 diabetes by regulating autoimmune effector T cells. Proc Natl Acad Sci U S A. 2013 Jun 11; 110(24):E2199-208. [PubMed: 23716674]

15. Fillatreau S, Sweenie CH, McGeachy MJ, Gray D, Anderton SM. B cells regulate autoimmunity by provision of IL-10. Nat Immunol. 2002 Oct; 3(10):944-50. [PubMed: 12244307]

16. Matsumoto M, Baba A, Yokota T, Nishikawa H, Ohkawa Y, Kayama H, et al. Interleukin-10producing plasmablasts exert regulatory function in autoimmune inflammation. Immunity. 2014 Dec 18; 41(6):1040-51. [PubMed: 25484301]

17. Ding Q, Yeung M, Camirand G, Zeng Q, Akiba H, Yagita H, et al. Regulatory B cells are identified by expression of TIM-1 and can be induced through TIM-1 ligation to promote tolerance in mice. J Clin Invest. 2011 Aug 8.

18. Mann MK, Maresz K, Shriver LP, Tan Y, Dittel BN. B cell regulation of CD4+CD25+ T regulatory cells and IL-10 via B7 is essential for recovery from experimental autoimmune encephalomyelitis. J Immunol. 2007 Mar 15; 178(6):3447-56. [PubMed: 17339439]

19. Yang M, Sun L, Wang S, Ko KH, Xu H, Zheng BJ, et al. Novel function of B cell-activating factor in the induction of IL-10-producing regulatory B cells. J Immunol. 2010 Apr 1; 184(7):3321-5. [PubMed: 20208006]

20. Yang M, Deng J, Liu Y, Ko KH, Wang X, Jiao Z, et al. IL-10-producing regulatory B10 cells ameliorate collagen-induced arthritis via suppressing Th17 cell generation. Am J Pathol. 2012 Jun; 180(6):2375-85. [PubMed: 22538089]

21. Carter NA, Vasconcellos R, Rosser EC, Tulone C, Munoz-Suano A, Kamanaka M, et al. Mice lacking endogenous IL-10-producing regulatory B cells develop exacerbated disease and present with an increased frequency of Th1/Th17 but a decrease in regulatory T cells. J Immunol. 2011 May 15; 186(10):5569-79. [PubMed: 21464089]

22. Natarajan P, Singh A, McNamara JT, Secor ER Jr, Guernsey LA, Thrall RS, et al. Regulatory B cells from hilar lymph nodes of tolerant mice in a murine model of allergic airway disease are CD5+, express TGF-beta, and co-localize with CD4+Foxp3+ T cells. Mucosal Immunol. 2012 Nov; 5(6):691-701. [PubMed: 22718263]

23. Blair PA, Norena LY, Flores-Borja F, Rawlings DJ, Isenberg DA, Ehrenstein MR, et al. CD19(+)CD24(hi)CD38(hi) B cells exhibit regulatory capacity in healthy individuals but are functionally impaired in systemic Lupus Erythematosus patients. Immunity. 2010 Jan 29; 32(1): 129-40. [PubMed: 20079667]

24. Matsushita T, Horikawa M, Iwata Y, Tedder TF. Regulatory B cells (B10 cells) and regulatory T cells have independent roles in controlling experimental autoimmune encephalomyelitis initiation and late-phase immunopathogenesis. J Immunol. 2010 Aug 15; 185(4):2240-52. [PubMed: 20624940]

25*. Lee KM, Stott RT, Zhao G, SooHoo J, Xiong W, Lian MM, et al. TGF-beta-producing regulatory B cells induce regulatory T cells and promote transplantation tolerance. Eur J Immunol. 2014 Jun; 44(6): 1728-36. TGF- $\beta$ expression by B cells may be necessary in Breg-mediated transplant tolerance. [PubMed: 24700192]

26. Ding, Q.; Rothstein, DM.; Yeung, M.; Najarian, N.; Sayegh, MH. Anti-TIM-4-induced islet allograft long-term survival is dependent on the presence of B cells. AST; Philadelphia: 2011. p. Abstract \#246 
27. Parekh VV, Prasad DV, Banerjee PP, Joshi BN, Kumar A, Mishra GC. B cells activated by lipopolysaccharide, but not by anti-Ig and anti-CD40 antibody, induce anergy in CD8+ T cells: role of TGF-beta 1. J Immunol. 2003 Jun 15; 170(12):5897-911. [PubMed: 12794116]

28. Tian J, Zekzer D, Hanssen L, Lu Y, Olcott A, Kaufman DL. Lipopolysaccharide-activated B cells down-regulate Th1 immunity and prevent autoimmune diabetes in nonobese diabetic mice. $\mathrm{J}$ Immunol. 2001 Jul 15; 167(2):1081-9. [PubMed: 11441119]

29. Wolf SD, Dittel BN, Hardardottir F, Janeway CA Jr . Experimental autoimmune encephalomyelitis induction in genetically B cell-deficient mice. J Exp Med. 1996 Dec 1; 184(6):2271-8. [PubMed: 8976182]

30. Ray A, Basu S, Williams CB, Salzman NH, Dittel BN. A novel IL-10-independent regulatory role for B cells in suppressing autoimmunity by maintenance of regulatory T cells via GITR ligand. $\mathbf{J}$ Immunol. 2012 Apr 1; 188(7):3188-98. [PubMed: 22368274]

31. Moreau A, Blair PA, Chai JG, Ratnasothy K, Stolarczyk E, Alhabbab R, et al. Transitional-2 B cells acquire regulatory function during tolerance induction and contribute to allograft survival. Eur J Immunol. 2015 Mar; 45(3):843-53. [PubMed: 25408265]

32. Shen H, Goldstein DR. IL-6 and TNF-alpha synergistically inhibit allograft acceptance. J Am Soc Nephrol. 2009 May; 20(5):1032-40. [PubMed: 19357252]

33*. Wang RX, Yu CR, Dambuza IM, Mahdi RM, Dolinska MB, Sergeev YV, et al. Interleukin-35 induces regulatory B cells that suppress autoimmune disease. Nat Med. 2014 Jun; 20(6):633-41. Together with reference 36, these two papers suggest a critical role for IL-35 in Breg function. [PubMed: 24743305]

34. Collison LW, Workman CJ, Kuo TT, Boyd K, Wang Y, Vignali KM, et al. The inhibitory cytokine IL-35 contributes to regulatory T-cell function. Nature. 2007 Nov 22; 450(7169):566-9. [PubMed: 18033300]

35. Collison LW, Chaturvedi V, Henderson AL, Giacomin PR, Guy C, Bankoti J, et al. IL-35mediated induction of a potent regulatory T cell population. Nat Immunol. $2010 \mathrm{Dec}$; 11(12): 1093-101. [PubMed: 20953201]

36*. Shen P, Roch T, Lampropoulou V, O’Connor RA, Stervbo U, Hilgenberg E, et al. IL-35producing B cells are critical regulators of immunity during autoimmune and infectious diseases. Nature. 2014 Mar 20; 507(7492):366-70. Together with reference 33, these two papers suggest a critical role for IL-35 in Breg function. [PubMed: 24572363]

37. Woodle ES, Rothstein DM. Clinical implications of basic science discoveries: janus resurrected-two faces of B cell and plasma cell biology. Am J Transplant. 2015 Jan; 15(1):39-43. [PubMed: 25382283]

38. Lee KM, Kim JI, Stott R, Soohoo J, O’Connor MR, Yeh H, et al. Anti-CD45RB/anti-TIM-1induced tolerance requires regulatory B cells. Am J Transplant. 2012; 12(8):2072-8. [PubMed: 22494812]

39. Ueno T, Habicht A, Clarkson MR, Albin MJ, Yamaura K, Boenisch O, et al. The emerging role of $\mathrm{T}$ cell Ig mucin 1 in alloimmune responses in an experimental mouse transplant model. J Clin Invest. $2008 \mathrm{Feb}$; 118(2):742-51. [PubMed: 18172549]

40. Xiao S, Brooks CR, Zhu C, Wu C, Sweere JM, Petecka S, et al. Defect in regulatory B-cell function and development of systemic autoimmunity in T-cell Ig mucin 1 (Tim-1) mucin domainmutant mice. Proc Natl Acad Sci U S A. 2012 Jul 24; 109(30):12105-10. [PubMed: 22773818]

41*. Yeung MY, Ding Q, Brooks CR, Xiao S, Workman CJ, Vignali DA, et al. TIM-1 Signaling Is Required for Maintenance and Induction of Regulatory B Cells. Am J Transplant. 2015 Apr; 15(4):942-53. Along with reference 42, this paper reveals the function of TIM-1 beyond serving as a biomarker. [PubMed: 25645598]

42*. Xiao S, Brooks CR, Sobel RA, Kuchroo VK. Tim-1 is essential for induction and maintenance of IL-10 in regulatory B cells and their regulation of tissue inflammation. J Immunol. 2015 Feb 15; 194(4):1602-8. Along with reference 41, this paper reveals the function of TIM-1 beyond serving as a biomarker. [PubMed: 25582854]

43. Nagata S, Hanayama R, Kawane K. Autoimmunity and the clearance of dead cells. Cell. 2010 Mar 5; 140(5):619-30. [Research Support, Non-U.S. Gov't Review]. [PubMed: 20211132] 
44. Martin F, Kearney JF. Marginal-zone B cells. Nat Rev Immunol. 2002 May; 2(5):323-35. [Review]. [PubMed: 12033738]

45. Miles K, Heaney J, Sibinska Z, Salter D, Savill J, Gray D, et al. A tolerogenic role for Toll-like receptor 9 is revealed by B-cell interaction with DNA complexes expressed on apoptotic cells. Proc Natl Acad Sci U S A. 2012 Jan 17; 109(3):887-92. [Research Support, Non-U.S. Gov't]. [PubMed: 22207622]

46. Yoshizaki A, Miyagaki T, DiLillo DJ, Matsushita T, Horikawa M, Kountikov EI, et al. Regulatory B cells control T-cell autoimmunity through IL-21-dependent cognate interactions. Nature. 2012 Nov 8; 491(7423):264-8. [PubMed: 23064231]

47. Roussey-Kesler G, Giral M, Moreau A, Subra JF, Legendre C, Noel C, et al. Clinical operational tolerance after kidney transplantation. Am J Transplant. 2006 Apr; 6(4):736-46. [PubMed: 16539630]

48. Newell KA, Asare A, Kirk AD, Gisler TD, Bourcier K, Suthanthiran M, et al. Identification of a B cell signature associated with renal transplant tolerance in humans. J Clin Invest. 2010 Jun 1; 120(6):1836-47. [PubMed: 20501946]

49. Sagoo P, Perucha E, Sawitzki B, Tomiuk S, Stephens DA, Miqueu P, et al. Development of a cross-platform biomarker signature to detect renal transplant tolerance in humans. J Clin Invest. 2010 Jun; 120(6):1848-61. [PubMed: 20501943]

50. Lozano JJ, Pallier A, Martinez-Llordella M, Danger R, Lopez M, Giral M, et al. Comparison of transcriptional and blood cell-phenotypic markers between operationally tolerant liver and kidney recipients. Am J Transplant. 2011 Sep; 11(9):1916-26. [PubMed: 21827613]

51. Chesneau M, Michel L, Dugast E, Chenouard A, Baron D, Pallier A, et al. Tolerant Kidney Transplant Patients Produce B Cells with Regulatory Properties. J Am Soc Nephrol. 2015 Feb 2.

52. Pallier A, Hillion S, Danger R, Giral M, Racape M, Degauque N, et al. Patients with drug-free long-term graft function display increased numbers of peripheral B cells with a memory and inhibitory phenotype. Kidney Int. 2010 Sep; 78(5):503-13. [PubMed: 20531452]

53. Iwata Y, Matsushita T, Horikawa M, Dilillo DJ, Yanaba K, Venturi GM, et al. Characterization of a rare IL-10-competent B-cell subset in humans that parallels mouse regulatory B10 cells. Blood. 2011 Jan 13; 117(2):530-41. [PubMed: 20962324]

54. Khoder A, Sarvaria A, Alsuliman A, Chew C, Sekine T, Cooper N, et al. Regulatory B cells are enriched within the IgM memory and transitional subsets in healthy donors but are deficient in chronic GVHD. Blood. 2014 Sep 25; 124(13):2034-45. [PubMed: 25051962]

55**. Cherukuri A, Rothstein DM, Clark B, Carter CR, Davison A, Hernandez-Fuentes M, et al. Immunologic human renal allograft injury associates with an altered IL-10/TNF-alpha expression ratio in regulatory B cells. J Am Soc Nephrol. 2014 Jul; 25(7):1575-85. [Research Support, NonU.S. Gov't]. Transitional B cell number and IL-10:TNF-a ratio may serve as biomarkers for transplant outcome. [PubMed: 24610932]

56. Bar-Or A, Fawaz L, Fan B, Darlington PJ, Rieger A, Ghorayeb C, et al. Abnormal B-cell cytokine responses a trigger of T-cell-mediated disease in MS? Ann Neurol. 2010 Apr; 67(4):452-61. [Clinical Trial, Phase I Randomized Controlled Trial Research Support, Non-U.S. Gov't]. [PubMed: 20437580]

57. Wojciechowski W, Harris DP, Sprague F, Mousseau B, Makris M, Kusser K, et al. Cytokineproducing effector B cells regulate type 2 immunity to H. polygyrus. Immunity. 2009 Mar 20; 30(3):421-33. [Research Support, N.I.H., Extramural Research Support, Non-U.S. Gov't]. [PubMed: 19249230]

58. Shabir S, Girdlestone J, Briggs D, Kaul B, Smith H, Daga S, et al. Transitional B Lymphocytes Are Associated With Protection From Kidney Allograft Rejection: A Prospective Study. Am J Transplant. 2015 Mar 23.

59. Viklicky O, Krystufkova E, Brabcova I, Sekerkova A, Wohlfahrt P, Hribova P, et al. B-cell-related biomarkers of tolerance are up-regulated in rejection-free kidney transplant recipients. Transplantation. 2013 Jan 15; 95(1):148-54. [PubMed: 23222918]

60. Leibler C, Matignon M, Pilon C, Montespan F, Bigot J, Lang P, et al. Kidney transplant recipients treated with belatacept exhibit increased naive and transitional B cells. Am J Transplant. 2014 May; 14(5):1173-82. [PubMed: 24730563] 
61. Clatworthy MR, Watson CJ, Plotnek G, Bardsley V, Chaudhry AN, Bradley JA, et al. B-celldepleting induction therapy and acute cellular rejection. N Engl J Med. 2009 Jun 18; 360(25): 2683-5. [PubMed: 19535812]

62. Bouaziz JD, Yanaba K, Venturi GM, Wang Y, Tisch RM, Poe JC, et al. Therapeutic B cell depletion impairs adaptive and autoreactive CD4+ T cell activation in mice. Proc Natl Acad Sci U S A. 2007 Dec 26; 104(52):20878-83. [PubMed: 18093919]

63. Tyden G, Mjornstedt L, Ekberg H. More on B-cell-depleting induction therapy and acute cellular rejection. N Engl J Med. 2009 Sep 17; 361(12):1214-5. author reply 5-6. [PubMed: 19759386]

64. Uchida J, Hamaguchi Y, Oliver JA, Ravetch JV, Poe JC, Haas KM, et al. The innate mononuclear phagocyte network depletes B lymphocytes through Fc receptor-dependent mechanisms during anti-CD20 antibody immunotherapy. J Exp Med. 2004 Jun 21; 199(12):1659-69. [PubMed: 15210744]

65. Yazawa N, Hamaguchi Y, Poe JC, Tedder TF. Immunotherapy using unconjugated CD19 monoclonal antibodies in animal models for B lymphocyte malignancies and autoimmune disease. Proc Natl Acad Sci U S A. 2005 Oct 18; 102(42):15178-83. [PubMed: 16217038]

66. Deng S, Moore DJ, Huang X, Lian MM, Mohiuddin M, Velededeoglu E, et al. Cutting Edge: Transplant Tolerance Induced by Anti-CD45RB Requires B Lymphocytes. J Immunol. 2007; 178(10):6028-32. [PubMed: 17475825]

67. Lal, G.; Tietjens, J.; van der Touw, W.; Yang, Y.; Ding, Y.; Ochando, JC., et al. B cell depletion prevents costimulatory blockade-induced tolerance. AST; Philadelphia: 2011. p. Abstract 484

68. van den Hoogen MW, Kamburova EG, Baas MC, Steenbergen EJ, Florquin S, HJMK, et al. Rituximab as induction therapy after renal transplantation: a randomized, double-blind, placebocontrolled study of efficacy and safety. Am J Transplant. 2015 Feb; 15(2):407-16. [PubMed: 25612493]

69. Anolik JH, Barnard J, Owen T, Zheng B, Kemshetti S, Looney RJ, et al. Delayed memory B cell recovery in peripheral blood and lymphoid tissue in systemic lupus erythematosus after B cell depletion therapy. Arthritis Rheum. 2007 Sep; 56(9):3044-56. [PubMed: 17763423]

70. Kamburova EG, Koenen HJ, van den Hoogen MW, Baas MC, Joosten I, Hilbrands LB. Longitudinal analysis of $\mathrm{T}$ and $\mathrm{B}$ cell phenotype and function in renal transplant recipients with or without rituximab induction therapy. PLoS One. 2014; 9(11):e112658. [PubMed: 25393622]

71. Liu C, Noorchashm H, Sutter JA, Naji M, Prak EL, Boyer J, et al. B lymphocyte-directed immunotherapy promotes long-term islet allograft survival in nonhuman primates. Nat Med. 2007 Nov; 13(11):1295-8. [PubMed: 17965721] 


\section{Key points}

- Several cell surface proteins, including TIM-1, enrich for regulatory B cells, however, IL-10 remains the definitive hallmark.

- Expansion of regulatory B cells may have potent anti-inflammation effects.

- A relative expansion of Bregs versus pro-inflammatory B cells may occur during recovery from $\mathrm{B}$ cell depletion and may promote allograft survival.

- Identification of a more definitive Breg phenotype will facilitate our ability to monitor their levels in vivo and test strategies to expand Bregs or avoid their depletion. 